\title{
Prototyping and Manufacturing of Magnetic Gearbox Components using Innovations in Castings
}
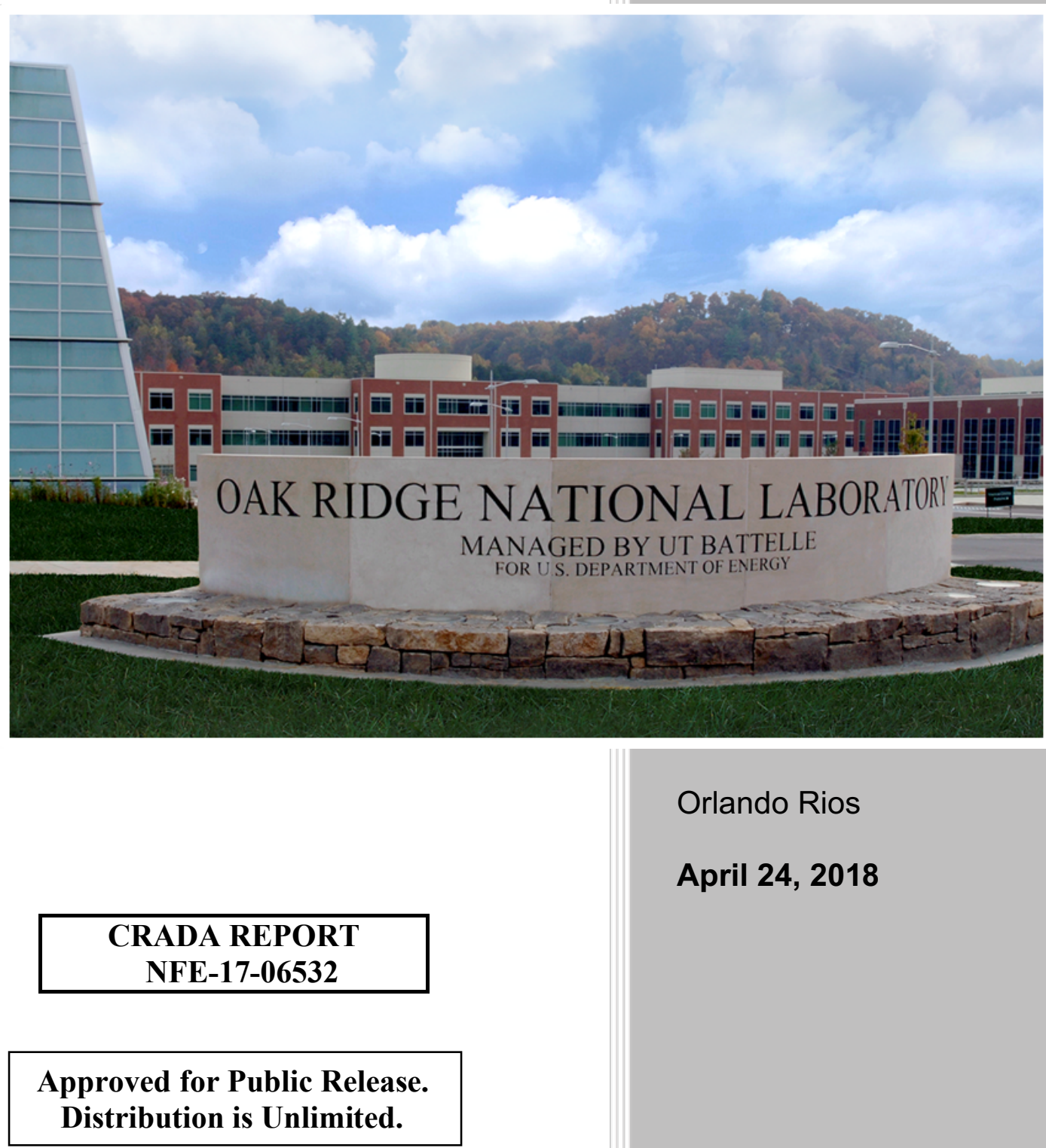

Orlando Rios

April 24, 2018 


\title{
DOCUMENT AVAILABILITY
}

Reports produced after January 1, 1996, are generally available free via US Department of Energy (DOE) SciTech Connect.

Website http://www.osti.gov/scitech/

Reports produced before January 1, 1996, may be purchased by members of the public from the following source:

\author{
National Technical Information Service \\ 5285 Port Royal Road \\ Springfield, VA 22161 \\ Telephone 703-605-6000 (1-800-553-6847) \\ TDD 703-487-4639 \\ Fax 703-605-6900 \\ E-mail info@ntis.gov \\ Website http://www.ntis.gov/help/ordermethods.aspx
}

Reports are available to DOE employees, DOE contractors, Energy Technology Data Exchange representatives, and International Nuclear Information System representatives from the following source:

Office of Scientific and Technical Information

PO Box 62

Oak Ridge, TN 37831

Telephone 865-576-8401

Fax 865-576-5728

E-mail reports@osti.gov

Website http://www.osti.gov/contact.htm|

This report was prepared as an account of work sponsored by an agency of the United States Government. Neither the United States Government nor any agency thereof, nor any of their employees, makes any warranty, express or implied, or assumes any legal liability or responsibility for the accuracy, completeness, or usefulness of any information, apparatus, product, or process disclosed, or represents that its use would not infringe privately owned rights. Reference herein to any specific commercial product, process, or service by trade name, trademark, manufacturer, or otherwise, does not necessarily constitute or imply its endorsement, recommendation, or favoring by the United States Government or any agency thereof. The views and opinions of authors expressed herein do not necessarily state or reflect those of the United States Government or any agency thereof. 
ORNL/TM-2018/907

CRADA/NFE-17-06532

Materials Science and Technology Division Advanced Manufacturing Office

\title{
PROTOTYPING AND MANUFACTURING OF MAGNETIC GEARBOX COMPONENTS USING INNOVATIONS IN CASTINGS
}

\author{
Authors \\ Hunter B. Henderson \\ Eric T. Stromme \\ Phillip Chesser \\ Zachary Sims \\ David Weiss \\ Lonnie Love \\ Bill Peter \\ PI's \\ Orlando Rios \\ Emily Morris, Emrgy, Inc.
}

Date Published:

April 24, 2018

\author{
Prepared by \\ OAK RIDGE NATIONAL LABORATORY \\ Oak Ridge, Tennessee 37831-6283 \\ managed by \\ UT-BATTELLE, LLC \\ for the \\ US DEPARTMENT OF ENERGY \\ under contract DE-AC05-00OR22725
}

Approved For Public Release 


\section{CONTENTS}

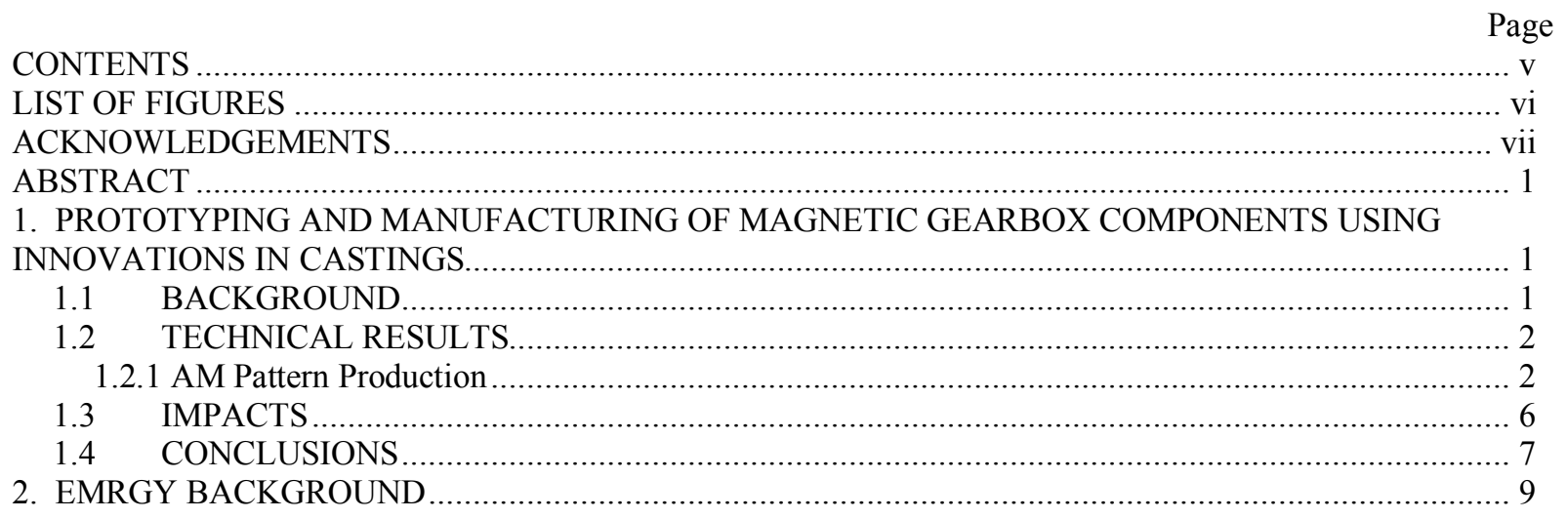




\section{LIST OF FIGURES}

Fig. 1. A) Original part design, B) cooling rate modeling, C) AM cope pattern, D) AM drag pattern, and E) cross-section of pattern showing sparse fill print method.

Figure 2: A) Pattern being coated with mold release. B) Cope pattern after separation from mounting plate. C)

Photo of cope mold after separation from pattern, showing partial failure due to pattern optimization issues......4

Fig. 3. A) Mounted drag pattern with cooling features installed, B) mounted cope pattern, C) sand mold

following removal from pattern, and D) casting part using sand mold. .......................................................

Fig. 4. Cast part, left: immediately after removal from the mold, right: after post processing ...........................6 


\section{ACKNOWLEDGEMENTS}

This CRADA NFE-17-06532 was conducted as a Technical Collaboration project within the Oak Ridge National Laboratory (ORNL) Manufacturing Demonstration Facility (MDF) sponsored by the US Department of Energy Advanced Manufacturing Office (CPS Agreement Number 24761).

Opportunities for MDF technical collaborations are listed in the announcement "Manufacturing Demonstration Facility Technology Collaborations for US Manufacturers in Advanced

Manufacturing and Materials Technologies" posted at http://web.ornl.gov/sci/manufacturing/docs/FBO-ORNL-MDF-2013-2.pdf. The goal of technical collaborations is to engage industry partners to participate in short-term, collaborative projects within the Manufacturing Demonstration Facility (MDF) to assess applicability and of new energy efficient manufacturing technologies. Research sponsored by the U.S. Department of Energy, Office of Energy Efficiency and Renewable Energy, Advanced Manufacturing Office, under contract DE-AC0500OR22725 with UT-Battelle, LLC. 


\begin{abstract}
This project combines additive manufacturing with the broadly deployed practice of metal casting. Combining these methods will unlock new design possibilities while reducing the economic burden of early stage prototyping while leveraging well established high throughput sand casting. Two main approaches are evaluated: direct printing of single use sand molds and printing of reusable impression patterns used to create sand molds. Reusable impression molds typically can be used to produce hundreds to several thousands of casting thereby amplifying the function of the 3D printed replica mold.

Emrgy's newly developed and tested proprietary magnetic gearbox system for low head hydroelectricity generation was the subject part of this study. Leveraging ORNL's additive manufacturing capability and expertise, a pattern impression was produced and used to create multiple sand molds of the gearbox during phase 1. Even before considering the cost savings possible once rigging and pattern mounting is optimized through repetition and improved design, final part costs using this combined method resulted in an $80 \%$ cost reduction over EMRGY's previous method of subtractive manufacturing for gearbox production.
\end{abstract}

\title{
1. PROTOTYPING AND MANUFACTURING OF MAGNETIC GEARBOX COMPONENTS USING INNOVATIONS IN CASTINGS
}

This phase 1 technical collaboration project (MDF-TC-2017-108) was begun on January 12, 2017 and was completed on September 30, 2017. The collaboration partner Emrgy, Inc.is a small business. This collaboration resulted in a positive outcome, showing reduced cost and less time between concept and prototype for pattern production using additive manufacturing methods.

\subsection{BACKGROUND}

Emrgy is a woman-owned startup company (2014) that has developed modular hydropower to be installed in man-made canals for hydrokinetic renewable energy generation. Standardized modular hydropower technologies represent an emerging renewable energy source that combines the high reliability and availability attributes of hydropower with the scalability and rapid growth potential of other modular technologies. The successful deployment of modular hydrokinetic systems will reduce the technological and economic barriers to new hydropower capacity by enabling efficient manufacturing, reducing infrastructure requirements and streamlining deployment times. The potential for continuous, baseload energy generation is a breakthrough for modular renewable equipment and will increase economic competitiveness of renewable generation and costeffectiveness of investments by reducing payback periods.

Emrgy's core technology builds upon a novel cycloidal magnetic gearbox innovation that has potential to measurably increase the reliability, efficiency and lifecycle of the hydropower drivetrain, which may radically improve the business case for developing distributed hydropower systems. As a small company, Emrgy has been prototyping the magnetic gearbox using subtractive manufacturing techniques, which is costly and time consuming. The team proposed to utilize additive manufacturing to produce patterns for sand castings that could increase the speed of production as well as reduce costs. 
The challenge addressed by this effort is to identify and verify potential fabrication methods that can improve the speed and cost-effectiveness of manufacturing the cycloidal magnetic gearbox system, thus leading to increased Technology Readiness Level (TRL). Success will be measured by the improvements in the time and cost to manufacture prototypes. During Phase 1 of this project, the team collaborated to address Emrgy's manufacturing challenge of producing prototype parts for testing.

Traditionally, cast parts are manufactured using a variety of casting methods including permanent mold (e.g. die-casting, gravity and low-pressure casting) and expendable mold methods (e.g. sand mold, pattern, and investment casting. Permanent mold methods (e.g. die casting) are generally used for high quantity applications because these methods are characterized by high fixed costs. When smaller production quantities, high performance, or more complex geometries are required, foundries generally utilize expansion molding techniques including sand molds.

The pattern approach is used to produce sand molds for large, complex parts. To produce parts using the pattern technique, a wood or plastic pattern is used to make a sand mold. Pattern development starts by separating the part design into two components, called the "cope" and "drag." The cope images the top/upper geometry of the part and the drag images the bottom/ lower geometry of the part. The two halves are imaged separately, because in the sand mold, the space between the two halves will allow molten metal to fill the mold and create the part. Once the part design is divided into two halves, the pattern is produced from a low-cost material, usually wood or high-density plastic. Pattern manufacture involves "subtractive" manufacturing by reducing a large block of material to the appropriate shape and size, either by hand or using a computer-numerical-control (CNC) machine tool. The initial block of material must be larger than the final part, increasing costs for large geometries.

\subsection{TECHNICAL RESULTS}

During phase 1 a pattern impression was produced using the state of the art Additive Manufacturing (AM) capabilities of the Oak Ridge National Laboratory (ORNL) Manufacturing Demonstration Facility (MDF). The polymer pattern was then mounted and used to produce a sand mold for full scale experimental casting trials. Time, cost, compatibility with existing foundry practices, and soundness of final part were all considered as criteria for success.

\subsubsection{AM Pattern Production}

Producing sand molds with reusable patterns reduces cost per part and lowers the normally high capital requirements for new companies pursuing prototype and early stage production components.

The first steps, which are similar to traditional pattern production methods, involve producing a modeled pattern from the desired part specifications. Unlike the previous production method for this part, direct machining from billet, the pattern approach (both traditional and AM) requires features that promote the flow of molten metal in the mold and that help to control solidification rate. As described above, this traditionally involves separating the pattern into two halves, the "cope" and "drag." For this particular part, the complexity required separately imaging the geometry of the interior of the part, called the "core box," in addition to the cope and the drag. Each portion of the pattern was manufactured using AM. The traditional, "subtractive" manufacturing approach results in increasing cost with increasing part complexity due to additional machining time and labor costs to 
position parts in the machine, supervise machine performance, and make adjustments. AM, conversely, requires less time to print complex geometries because instead of removing material to create features, features are produced in their final condition. For example, in this pattern, the end user's goal was to reduce final part weight by designing "cutouts" in non-structural areas of the part. In traditional machining, each of these cutouts would require additional machining time to remove material from the block. In the AM approach, these the features were printed as part of the process and actually reduced build time (since less total material was required). AM also allows more flexibility in pattern design by avoiding position limitations inherent in Computer Numerical Control (CNC) machining processes. As part complexity increases, the relative benefit of AM over CNC machining increases. To leverage this strength of the AM approach, the original part design was modified to reduce weight and material use.

Since the cope and drag patterns each only imaged half of the part, they could be easily printed without the need for supporting overhangs, realizing additional time and print material savings. Only one side of each pattern has part geometry, which allows the other side to be designed to limit use of support material. Fig. 1E illustrates this processing, termed "sparse fill", which drastically increased the printing speed and reduced material cost. A sparse fill of approximately $2 \%$, was used in pattern manufacture resulting in outer "skin" of the part approximately 0.100 inches thick. The sparse fill approach required 84 hours of print time and $260 \mathrm{in}^{3}$ of material. Alternatively, printing a solid cope pattern would have required 467 hours and $1664 \mathrm{in}^{3}$ of material. The sparse fill approach represents print time and material reductions of $82 \%$ and $85 \%$, respectively, when compared to printing a solid part. Patterns were printed using a Stratasys Fortus $900 \mathrm{mc}$, which has a build envelope of 36 "x24"x36", ideal for the part which is the subject of this study (23.2 inches in diameter and 11.7 inches tall).

The pattern was printed from ULTEM (amorphous thermoplastic polyetherimide resin) which combines high dimensional resolution with suitable mechanical properties. Because of the size of the part, a rigid material was required to prevent cracking and bending when sand is poured on top of the pattern. The large molds were printed using several interlocking sections that could be assembled into a mold box. Typically, this mold design would require over 100 individually machined components that are hand assembled. AM was able to reduce touch manufacturing and assembly. Domestically, touch manufacturing is the most costly step in mold production.

Next, as in the printed mold trial, Magma ${ }^{\circledR}$ was used to model and analyze the part's anticipated cooling rate. Results of the modeling, shown in Fig. 1B, were used to determine placement of "chills" (small heat conducting rods or blocks) and other devices needed to accelerate or retard local cooling rates. These features were added to the pattern prior to filling with sand as shown in Fig 3A. The printed pattern and gating was then mounted into a box; forming the fill volume needed to make the sand mold. The gating and pattern were printed separately to allow tailoring of gating/rising features to the thermodynamic properties of the casting alloy. The pattern and mold box were painted and mold-release agent was applied to ease in mold removal, Fig 2A.

In traditional pattern production, additional labor is often required to reduce surface roughness of the pattern. Excessive roughness on the pattern or high depth to width ratio on design features inhibits separation of the sand mold from the pattern. High speed CNC machines, particularly when used with wood or plastic materials, often leave rough surfaces that require additional steps to correct. This study sought to produce a pattern with inherently low surface roughness by selecting a printer and material that would produce smooth, polymer parts, eliminating these additional labor cost. The Stratasys Fortus printer and ULTEM material met these objectives. Additionally, ULTEM was used because it does not react chemically with common "mold release" agents routinely used to promote mold-pattern separation. 
The sand and binder mixture was poured around the pattern forming the sand mold. After this mixture solidified, the sand mold was manually removed from the pattern. During removal of the cope mold, however, the pattern remained attached to the sand due to a failure of the pattern at the connection point to the mold box, Fig 2B. Because of the sparse fill construction, the stress at the connection points was too great, resulting in failure at the connection points. To correct this deficiency, epoxy was added in the sparse-fill void space near the connection points to strengthen the pattern. The pattern was then re-mounted in the mold box. These repairs resulted in additional labor cost and delayed production. Future trials may focus on optimizing fill parameters to strengthen pattern near mounting points.
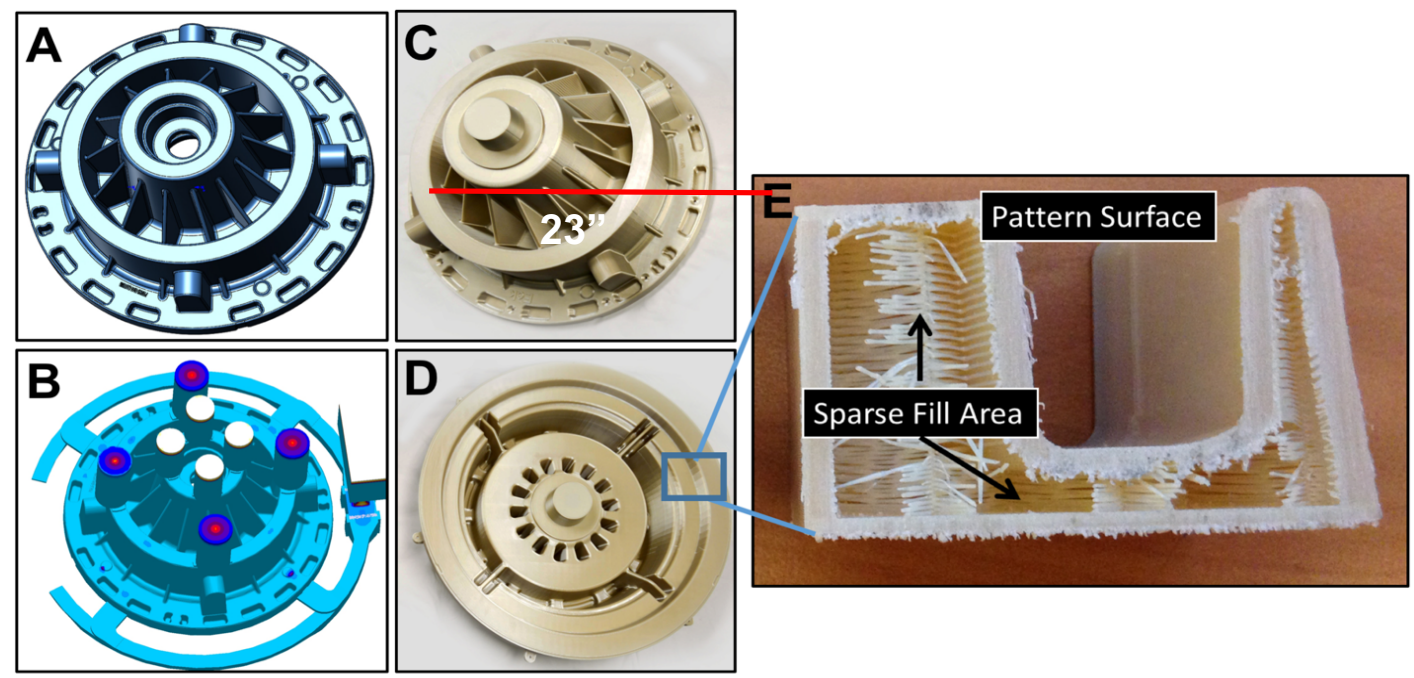

Fig. 1. A) Original part design, B) cooling rate modeling, C) AM cope pattern, D) AM drag pattern, and E) cross-section of pattern showing sparse fill print method

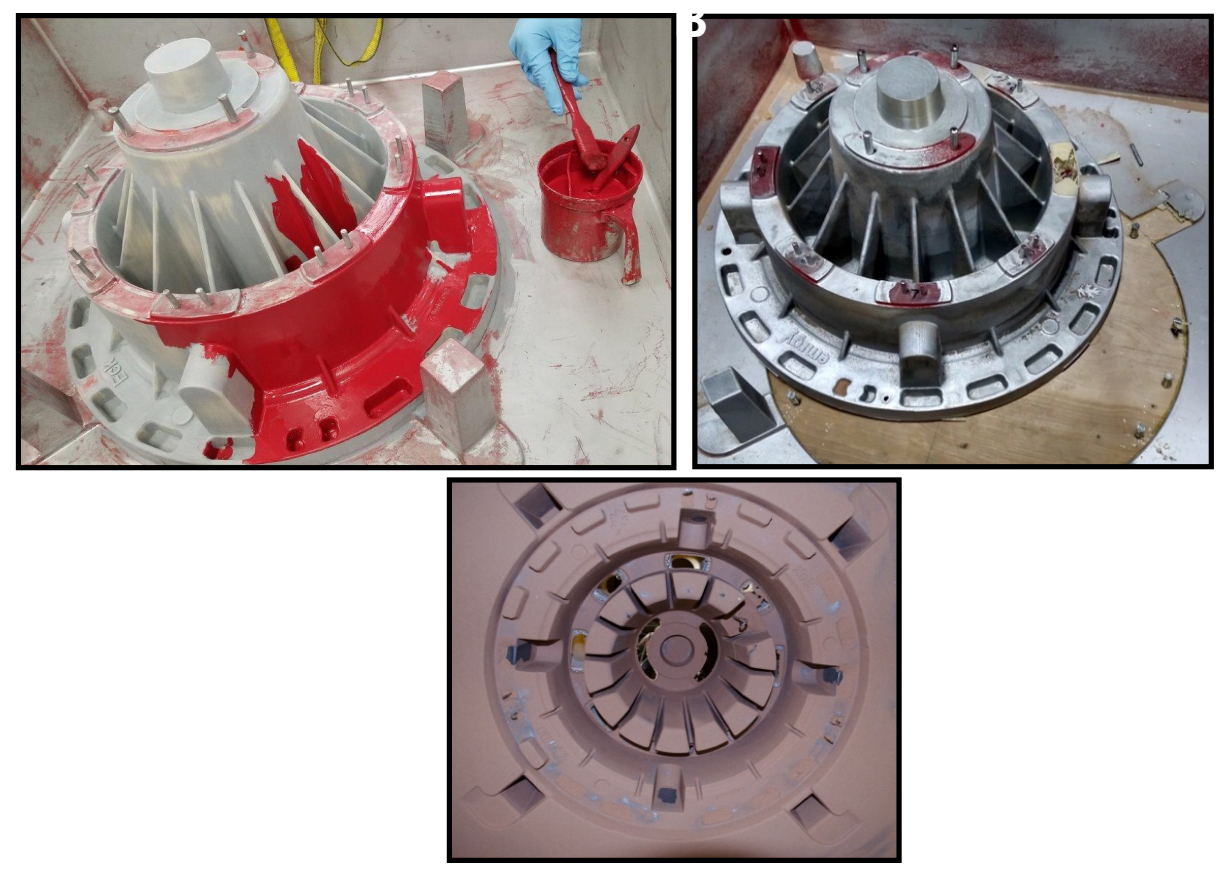

Figure 2: A) Pattern being coated with mold release. B) Cope pattern after separation from mounting plate. C) Cope mold after separation from pattern, with partial failure due to pattern optimization issues. 

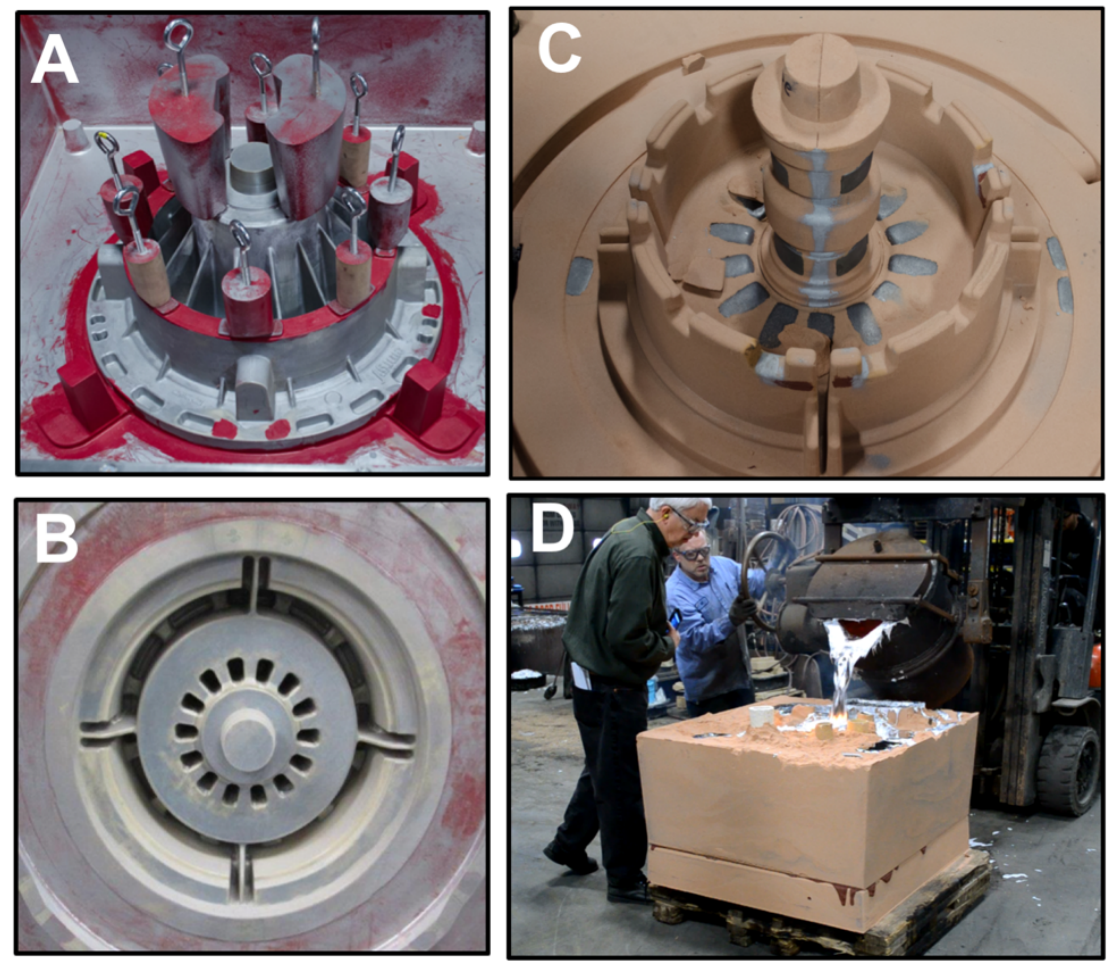

Fig. 3. A) Mounted drag pattern with cooling features installed, B) mounted cope pattern, C) sand mold following removal from pattern, and D) casting part using sand mold.

Once the pattern was re-mounted, the sand-adhesive mixture was poured onto the pattern to create the sand mold shown in Fig. 3C. Following solidification, the sand mold was removed from the pattern. When separating the sand mold from the pattern, however, some features broke off the mold and remained in the pattern, Fig 2C. This effect is a common problem with complex pattern designs with shallow draft angles. Generally, pattern makers limit the overall feature depth and feature depth to width ratio to ensure the sand-adhesive bond is strong enough to remove the features from the pattern. This pattern was not designed with those considerations, instead emphasizing the shape flexibility afforded by AM to minimize material use. Mold-pattern separation concerns were not evaluated during the design phase. As a result, some features initially did not "pull" (i.e. the features did not transition from the pattern to the sand mold). To correct this issue, some pattern surfaces identified as problem areas were smoothed and draft angles were adjusted. Additionally the patterns were internally reinforced during printing. This is accomplished by including thick walled tubular structures that can be used as anchor points to the mold box and reinforced with reactive polymers. These modifications resulted in satisfactory mold/pattern separation for end user needs, but added additional in process cost.

Following optimization of the pattern and successful creation of the cope, drag, and core box sand molds, these portions were combined to create the final mold. Molten aluminum was then poured into the mold, flowing between the cope, drag, and core box to create the final part. Following solidification, the sand was manually removed from the part using mechanical agitation. The final part before and after post-processing is seen in Fig. 4. 


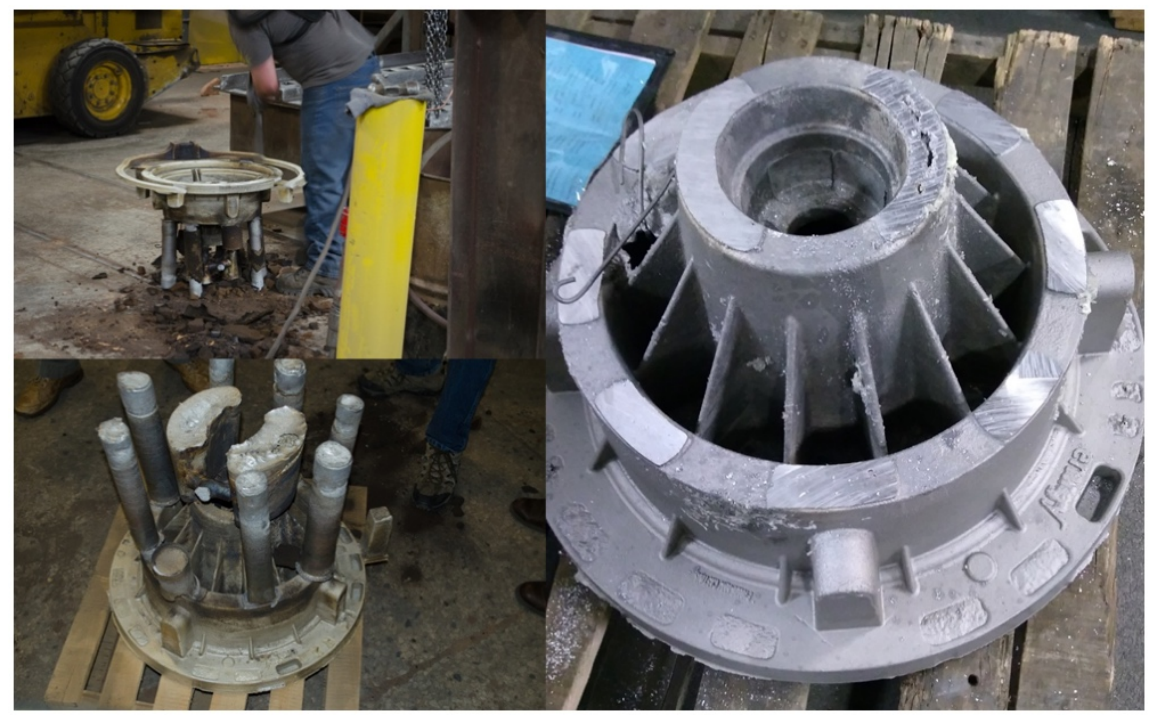

Fig. 4. Cast part, left: immediately after removal from the mold, right: after post processing

\subsection{IMPACTS}

Additively manufactured patterns have the potential to reduce both production costs and time for complex, large size (i.e. parts with any dimension of approximately 12 inches or greater) castings. This study demonstrates that for small quantity or large part manufacturing, the higher material cost of AM methods is offset by savings in labor costs and CNC machine time for complex parts. AM is competitive for industrial scale sand casting. Tables 1 and 2 compare the cost and production time between the AM approaches and quoted cost and timeline for a traditional pattern. Cost figures are calculated using a machine cost of $\$ 65$ per hour, which is based on quoted costs from pattern vendors.

Table 1: Production of Pattern Using Stratasys System

\begin{tabular}{|c|c|c|}
\hline & $\begin{array}{c}\text { Conventional Pattern } \\
\text { (Quote) }\end{array}$ & AM Pattern (Actual) \\
\hline Build/Print Cost (Time) & $\$ 14,820(228$ Hours) & $\$ 12,610$ (194 Hours) \\
\hline $\begin{array}{c}\text { Pattern Rigging Cost } \\
\text { (Time) }\end{array}$ & $\$ 4,550$ (70 Hours) & $\$ 2,600$ (40 Hours) \\
\hline Material Cost & $\$ 2,000$ & $\$ 4,700$ \\
\hline Total Cost & $\$ 21,370$ & $\$ 19,910$ \\
\hline
\end{tabular}

Table 2: Production of Pattern using BAAM System

\begin{tabular}{|c|c|l|}
\hline & $\begin{array}{c}\text { Conventional Pattern } \\
\text { (Quote) }\end{array}$ & AM Pattern (Actual) \\
\hline Build/Print Cost (Time) & $\$ 5,600$ & $\begin{array}{l}\$ 260 \text { (4 Hours Printing) } \\
\$ 260 \text { (4 Hours Machining) }\end{array}$ \\
\hline $\begin{array}{c}\text { Pattern Rigging Cost } \\
\text { (Time) }\end{array}$ & $\$ 3,300$ & $\$ 5,130$ (80 Hours) \\
\hline Material Cost & $\$ 2,000$ & $\$ 400$ \\
\hline Total Cost & $\$ 10,900$ & $\$ 6,050$ \\
\hline
\end{tabular}

The BAAM approach represents a large relative cost savings over both traditional pattern production and pattern production using the Stratasys system. However, due to the high surface 
roughness and layer thickness of the BAAM, its application would be limited to large castings of medium complexity or less. The Stratasys system, though more expensive than BAAM, is less costly than traditional methods and the smooth surface of the as-printed part combined with very high spatial resolution makes this type of printer a good choice for small complex castings. Despite the relative immaturity of the technology, when compared to established pattern production techniques, the AM approach saved both time and cost for complex parts. Traditional manufacturing methods require labor intensive material removal and smoothing of pattern surfaces. By comparison, AM is a fully automated process resulting in a smooth surface finish, reducing labor costs and eliminating pattern smoothing steps. The automation of the process, allowing production without input from work force, enables additional labor cost savings.

In both the BAAM and Stratasys scenarios pattern rigging accounts for a significant portion of the cost. For example, in the case of the BAAM system over 5000 dollars of the 6000 dollar cost is contributed by the pattern rigging costs. Due to the novelty of these parts and the foundry's lack of experience handling and mounting them the cost was heavily inflated. Rigging cost is not an inherent result of the AM process and can be mitigated through improved designs and worker experience. As the rigging process is repeated, allowing the team to become more familiar with the process, providing pattern design feedback as well, this step is expected to become less costly and time consuming. Therefore with each iteration of the design to pattern to mold process total cost savings only increases.

Two papers are under construction and will be submitted soon which use data and images generated during this project. The first will be a focused work on case studies of printable patterns and will be published in a journal with heavy industry focused readership. The second will be a paper on sustainable engineering and will be initially submitted in one of the newer Nature or Elsevier journals on this subject.

\subsubsection{Subject Inventions}

There are no subject inventions associated with this CRADA .

\subsubsection{Publications}

Two papers are being written and will be submitted which use data and images generated during this project. The first will be a focused work on case studies of printable patterns and will be published in a journal with heavy industry focused readership. The second will be a paper on sustainable engineering and will be initially submitted in one of the newer Nature or Elsevier journals on this subject.

\subsection{CONCLUSIONS}

Phase 1 successfully demonstrated the use of additively manufactured patterns to cost-effectively produce parts for use in a magnetic gearbox, which will be used in renewable hydropower generation. The work completed in this Technical Collaboration has resulted in significant cost savings per part for Emrgy prototypes. Compared to the subtractively manufactured prototype cost of $\$ 9,000$, prototypes manufactured using the AM Patterns developed in this Technical Collaboration are projected to cost only $\$ 1900$ - representing part cost savings of almost $80 \%$. This technique is believed to enable Emrgy to execute a comprehensive testing program to expedite commercialization of this technology.

These prototype parts will be lab tested later in 2018, and subsequently installed in fully functional hydroelectric generator prototypes and implemented in a comprehensive testing program 
during 2018-2019. It is expected these parts and other produced using this transformational process will be deployed into the field.

The proposed phase 2 of this project will focus on the use of this methodology to produce optimized, cost-effective prototype parts for the rest of Emrgy's magnetic gearbox design including: gearing, electromagnetic, and power transfer components. This approach will enable Emrgy to not only continue to improve cost and production speed, but realize these improvements for scaled performance and durability testing. The appropriate molds will be fabricated and tested so that comparative data can be gathered and analyzed. During phase 2 Emrgy will provide measurable cost share on the production of these new parts and their geometries. 


\section{EMRGY BACKGROUND}

Emrgy is a transformational technology company that is redefining hydropower to be characterized by the same attributes that have made the wind and solar power industries grow exponentially over the past several decades: modularity and flexibility. Using innovative hardware and software technology, Emrgy enables customers to tap into unused energy resources in small or shallow water flows to reduce grid power consumption and/or achieve grid power independence.

Emrgy's technology has been developed with over \$2 million in Federal investment from the US Department of Energy and the US Office of Naval Research, and our team has collaborated with researchers from Georgia Tech, Cardiff University, IEEE and Drive System Design to ready the product for deployment. The heart of the system is a proprietary magnetic gearbox that overcomes the maintenance and life compromises of conventional mechanically-geared turbines, representing a breakthrough in kinetic power conversion. 